\title{
Clinical study on the comparison of masticatory efficiency and jaw movement before and after temporomandibular disorder treatment
}

\author{
Kümbüloğlu, Ovül ; Saracoglu, Ahmet ; Bingöl, Pinar ; Hatipoğlu, Anil ; Özcan, Mutlu
}

\begin{abstract}
In this clinical study, pre- and post-rehabilitation changes in intraborder mandible movements, chewing cycles, masticatory efficiencies, and borders of the chewing area of patients with unilateral muscular disorders (MD) $(\mathrm{n}=20)$ or unilateral disc derangement disorders (DDD) $(\mathrm{n}=20)$ of temporomandibular disorder (TMD) were observed and compared with healthy individuals with full dentition $(n=20)$ (48 female, 12 male; mean age: 28). The MD patients received stabilization splints and the DDD patients, anterior positioning splints for six weeks. Symptoms, such as muscle pain, TMJ pain, headache, chewing difficulty, and maximum mouth opening, showed significant improvements after splint therapy for both MD $(\mathrm{p}=0.000)$ and DDD $(\mathrm{p}=0.000)$ patients, but lateral excursion and protrusion were not significantly changed $(p>0.05)$. Chewing efficacy and chewing cycles improved significantly $(\mathrm{p}<0.05)$ in both the MD $(\mathrm{p}<0.05)$ and $\mathrm{DDD}(\mathrm{p}<0.05)$ groups, but only the MD group was comparable to the control group after treatment. Pre- and post-rehabilitation chewing cycles along the frontal plane on both sides in the MD group were similar to the control group. Considering the majority of the improvements in the diagnostic measures, patients with MD and DDD may benefit from occlusal splint therapy.
\end{abstract}

DOI: https://doi.org/10.1179/crn.2013.030

Posted at the Zurich Open Repository and Archive, University of Zurich

ZORA URL: https://doi.org/10.5167/uzh-89932

Journal Article

Accepted Version

Originally published at:

Kümbüloğlu, Ovül; Saracoglu, Ahmet; Bingöl, Pinar; Hatipoğlu, Anil; Özcan, Mutlu (2013). Clinical study on the comparison of masticatory efficiency and jaw movement before and after temporomandibular disorder treatment. Cranio: Journal of Craniomandibular Practice, 31(3):190-201.

DOI: https://doi.org/10.1179/crn.2013.030 
Clinical Study on the Comparison of Masticatory Efficiency and Jaw Movement Before and After Temporomandibular Disorder Treatment

Ovul Kumbuloglu, D.D.S., Ph.D ${ }^{1}$; Ahmet Saracoglu, D.D.S., Ph.D ${ }^{1}$, Pinar Bingol, D.D.S. ${ }^{1}$ Anil Hatipoglu, D.D.S., Ph.D²; Mutlu Özcan, D.D.S., D.M.D., Ph.D³

${ }^{1}$ Ege University School of Dentistry Dept. of Prosthodontics, İzmir, Turkey

${ }^{2}$ Private Practice, İzmir, Turkey

${ }^{3}$ University of Zurich, Dental Materials Unit, Center for Dental and Oral Medicine, Clinic for Fixed and Removable Prosthodontics and Dental Materials Science, Zurich, Switzerland

Address for correspondance:

Prof. Dr. Mutlu Özcan

University of Zurich, Center for Dental and Oral Medicine,

Zurich, Switzerland

Email: mutluozcan@hotmail.com 
Dr. Övül Kümbüloğlu works at the Ege University, Dentistry Faculty, Department of Prosthodontics in Izmir, Turkey. She has authored close to 100 scientific articles at national and international journals. She serves also for the editorial boards of several scientific journals, is a member of the scientific comission for the Aegean Region Chamber of Dentisry. She has given numerous hands-on courses especially on dental implantology ve adhesive dentistry subjects. She is the board member of Turkish Association of Prosthodontics and Implantology (TPID) and member of International Association for Dental Research (IADR).

Dr. Ahmet Saraçoğlu graduated from Ege University, Dentistry Faculty in 1986. He did his PhD at Ege University, Dentistry Faculty, Department of Prosthodontics in Izmir, Turkey. After he completed his PhD thesis entitled 'In vivo and in vitro evaluation of occlusal splint and occlusal adjustment efficieny in bruxist patients', in 1994, he bacame an associate professor in 2004, and full professor in 2009. He is the member of Turkish Association of Prosthodontics and Implantology (TPID), International Research Diagnostic Criteria for Temporomandibular Disorders (RDC/TMD), Prosthetic Association of College of Gnatology (PAGD), and also board member of Turkish Association of Prosthodontics and Implantology (TPID) Izmir.

Dr. Pınar Bingöl graduated from Ege University, Dentistry Faculty in Izmir, Turkey in 2008 and started her $\mathrm{PhD}$ at Ege University Dentistry Faculty, Department of Prosthodontics. She is the member of International Team for Implantology (ITI) and International Association for Dental Research (IADR).

Dr. Anıl Hatipoğlu graduated from Gazi University, Dentistry Faculty in Ankara, Turkey in 2004 and started his PhD at Ege University, Dentistry Faculty, Department of Prosthodontics in Izmir, Turkey. He completed his thesis entitled 'Comparison of masticatory efficiency and chewing movement before and after temporomandibular disorder treatment. Since 2009 he has been working at the private sector.

Dr. Mutlu Özcan received her D.D.S. degree from University of Marmara, Istanbul, Turkey, D.M.D from University of Cologne, Germany and her Ph.D from University of Groningen, The Netherlands. She is currently the Head of Dental Materials Unit at the University of Zurich, Dental School, Zurich, Switzerland. She has authored more than 200 scientific and clinical articles in peer-reviewed journals, has given over 300 presentations at international scientific meetings, is a frequent lecturer, receiver of several international awards and has held numerous continuing education courses in Europe. She serves also for the editorial boards of several scientific journals. She has Visiting Professor positions at various universities including São Paolo State University (Brazil), Federal University of Juiz de Fora (Brazil), University of Brno (Czech Republic), University of Florida (USA) and University of Groningen (The Netherlands). 
ABSTRACT: In this clinical study, pre- and post-rehabilitation changes in intraborder mandible movements, chewing cycles, masticatory efficiencies and borders of chewing area of patients with unilateral muscular disorders (MD) $(n=20)$, unilateral disc derangement disorders (DDD) $(n=20)$ of temporomandibular disorder (TMD) were observed and compared with healthy individuals with full dentition ( $n=20$ ) (48 female, 12 male; mean age: 28 ). MD patients received stabilization splints and DDD patients anterior positioning splints for a duration of 6 weeks. Symptoms such as muscle pain, TMJ pain, headache, chewing difficulty, maximum mouth opening showed significant improvements after splint therapy for both MD $(p=0.000)$ and DDD $(p=0.000)$ patients but lateral excursion and protrusion were not significantly changed $(p>0.05)$. Chewing efficacy and chewing cycles improved significantly $(p<0.05)$ in both MD $(p<0.05)$ and DDD $(p<0.05)$ groups but only MD group was comparable to control group after treatment. Pre- and post-rehabilitation chewing cycles along frontal plane on both sides of MD group were similar to control group. Considering the majority of the improvements in the diagnostic measures, patients with MD and DDD may benefit from occlusal splint therapy. 


\section{Introduction}

Temporomandibular disorders might strongly affect the life quality of the patients as they affect the eating and speaking negatively. This disorder is classified under two main groups namely, functional disorders of the muscular disorders (TMD) and functional disorders of the temporomandibular joints (TMJ). ${ }^{1}$

Both TMD and TMJ could be treated in the first place with conservative treatment methods such as splint therapy. ${ }^{2,3}$ For this purpose, typically stabilization splints are used made of acrylic plates that prevent the teeth interference during jaw movements. Stabilization splints help to reduce the abnormal muscle activities in masticatory muscles, especially in lateral pterygoid muscle. While intending to form balanced contacts with contary teeth, they also help to achieve canine guidance. ${ }^{4,5}$ On the other hand, anterior positioning splints have guide slopes that helps the mandible to close in a new mandibular position instead of the habitual one and also they have the guide pits for the teeth to fit. Moreover, they are used to direct the mandible to the anterior position. Anterior positioning splints are widely used in the treatment of disc deplacements with the aim of fixing the condyl-disc relation and to improve the adaptation and repair of tissues. With the use of this splint, complete elimination of complaints is not expected. However, these appliances could reduce the joint pain, sounds, secondary muscle symptoms, or inflammations formed by the dics displacement. Patients who have problems such as joint sound, chronic jaw locking and some inflammatory problems could benefit from protrusive splint treatment. ${ }^{6}$

Limited jaw movements are one the most important signs of TMD. Changes of the jaw movements are determined with kinesiography methods with which maximum mouth opening, protrusion and lateral excursion measurements can be evaluated for the diagnostics of TMJ function or disfunction..$^{7,8}$

The objectives of this study were to evaluate the pre- and post-rehabilitation changes in patients with unilateral muscular disorders (MD), unilateral disc derangement disorders (DDD) after splint therapy, compare the results with healthy individuals and assess the effectiveness of kinesiography methods in the diagnosis and treatment of TMD. 


\section{Materials and Methods}

\section{Study population}

Data of the present study were collected from 40 consecutive patients seeking treatment for TMD at the Ege University, School of Dentistry Department of Prosthodontics. Patients who joined the study read the informed consent form and their approval were registered. The Ethical Committee in Human Research of University of Ege approved the protocol of this research (Number: 07-4.1/7, 01.05.2007). Patients who have missing teeth, neurological disorders or use drugs that could affect the muscle activity, were excluded from the study.

Patients with unilateral muscular disorders (MD) $(n=20)$, unilateral disc derangement disorders (DDD) $(n=20)$ of TMD and healthy individuals with full dentition $(n=20)$ were enrolled in this study (48 female, 12 male; mean age: 28 , between $20-55$ years of age). The aim of choosing MD and DDD was to evaluate the differences between masticatory cycles and intraborder movements while chewing with both the affected and the unaffected side.

\section{Clinic evaluation protocol}

Anamnesis was taken from the patients, their complaints were listened, clinical observations were made, and muscles and TMJ were examined. Masticatory muscle, subhyoid and suprahyoid muscle and headneck muscle examinations were made with palpation. Tense areas and pain localizations were identified. Masseter was palpated at its attachments to the zygomatic arch and angle of the mandible. The temporalis both in the temporal fossa and intraorally along the ascending ramus of the mandible, the medial pterygoid were examined bimanually, placing one finger externally at the medial aspect of the angle of the mandible and the other finger intraorally in the lingual vestibule in the retromolar region. Lateral pterygoid muscle was palpated behind tuber maxilla towards medial but the anatomical positon of this muscle makes palpation ineffective. Thus, a second method called functional manipulation was 
applied to the patients. Digastric muscle was palpated in the mid point of the distance between angulus mandibula and the jaw. ${ }^{1}$

Condyle movements were observed during mouth opening. Maximum mouth opening, protrusion and the amount of lateral excursions were evaluated. Joint and disc sound complaints were confirmed by listening. The presence of DDD was confirmed with Magnetic Resonance Imaging (MRI). Visual analog scale (VAS) and Research Diagnostic Criteria for Temporomandibular Disorder (RDC/TMD) forms were filled in before and after treatment. The meaning of scores for VAS ranging from 0 (no pain) to 10 (severe pain) was explained to the patients. Medium level pain was scored with 5 . Patients were asked to mark the levels of muscle pain (0-10), disc/joint pain (0-10), headache (0-10) and difficulty of chewing (0-10) on the scale.

\section{Preparation of occlusal splints}

Stabilization splints were prepared for patients with MD using auto-polymerized acrylic (Vertex Orthoplast, Zeist, Holland). Splints were applied on the upper jaw. Alginate impressions made from maxilla and mandible was poured with plaster (Shera, Lemförde, Germany) to obtain the models. Equal to the planned splint thickness $(-2 \mathrm{~mm})$, patient bit a piece of wax. Both maxilla and mandible models were mounted to the articulator. Undercuts that could interfere with the fit of the splint were filled. Autopolymerized acrylic dough was prepared with appropriate powder-liquid proportion applied to the plaster model leaving the half of the buccal sides of teeth uncovered and all teeth surfaces with $1 / 3$ of the palate covered. Acrylic plate was processed in hot vacuum. After finishing essential occlusal preparations in the articulator, the plate was applied to the patient. Canine protected occlusion, equal and balanced contact was supplied to all teeth with splints. Patients were advised to use the splints for six weeks, all day and night except during eating and brushing teeth. Patients were proposed to have a mild diet and were warned about wrong habits and their parafunctions. 
In the treatment of patients with DDD, anterior positioning splints made of auto-polymerized acrylic were used. Initially, stabilization type of splints was made to the patients as described above. Patient's adaptation to the splint was achieved during the following three weeks. In order to ensure proper condyledisc relationship, mandible was moved to the appropriate anterior position and stabilized by autopolymerized acrylic. After proper condyle-disc relationship was stabilized, mandible was moved to the centric relation position by grinding the anterior positioning splint. Splint was used for six weeks all day and night except during eating and tooth brushing.

\section{Intraborder movements and chewing cycles}

Computerized mandibula scanner (K7, Myotronics, WA, USA) was used in order to determine maximum mouth opening, protrusion, lateral excursions at the affected and unaffected sides, chewing cycles, chewing areas in the frontal, sagital and horizontal plane while chewing, before and after treatment. The registrations were made at the beginning of the treatment of patients with MD and DDD and also after the 6th week of splint use.

For reliable registration, patients were made to sit upright. Computerized mandibule scanner magnet (12 $\mathrm{mm} \times 6 \mathrm{~mm} \times 3 \mathrm{~mm}$ ) was glued with an easily removable sticky gel onto the middle line of lower incisors in a way that they did not contact with upper teeth while closing and without disturbing lower lip (Fig. 1). The part of computerized mandible scanner that registers the jaw movements to the computer was applied to the patient by the support of nose and head (Fig. 2). While mandible was moving, the sensor of computerized mandibula scanner recorded the movements of the magnet to the computer.

Firstly, maximum mouth opening, protrusion, lateral excursions of the affected and unaffected sides were recorded by no. 13 mandible kinesiography program. Patients were asked to open their mouth from the centric occlusion position to the maximum. Next, the mandible was closed to centric occlusion position again. Without losing tooth contact, mandible was moved firstly to the affected side and then to the unaffected side. Finally, patients were asked to move their mandible to maximum protrusion position 
and after getting the jaw to centric occlusion again, intraborder measurements were completed. At the second step, no. 1 mandible kinesiography program was used to record the chewing cycles during mandible movement. Patients were given chewing gums and were asked to soften them. After the chewing gum softened, patients chewed the gum first with the affected side and then with the unaffected side and finally they were let to chew freely ten times. Chewing cycle records were loaded to computer. Healthy individuals were also asked to chew gums in a freeway and registrations were made in the similar manner.

\section{Chewing cycle types}

Masticatory cycle type during chewing in the frontal line was classified as drop (F-I), semi-oval (F-II) and narrow-long (F-III). According to the maximum wideness during opening and closing, while chewing cycle on the sagittal line was classified as less than $2 \mathrm{~mm}(\mathrm{~S}-\mathrm{I})$ and more than $2 \mathrm{~mm}(\mathrm{~S}-\mathrm{II})$, chewing cycle on the horizontal line was classified as less than $2 \mathrm{~mm}(\mathrm{H}-\mathrm{I})$ and more than $2 \mathrm{~mm}(\mathrm{H}-\mathrm{II})$.

\section{Chewing areas}

In order to determine chewing areas, chewing cycles were recorded by the mandible kinesiograph. The measurement was based on the movement lines on the outer space of previous chewing cycles. Cycle area that is in the border was painted and calculated in $\mathrm{mm}^{2}$ using the corresponding software (Image Tool, CNET, CA, USA).

\section{Masticatory efficiency}

Masticatory efficiency was calculated based on the chewing efficacy of gelatin cubes. Gelatin leaves (180 g) were melted in a closed glass container filled with $1000 \mathrm{~mm}$ pure water at $60^{\circ} \mathrm{C}$. Prepared solution was poured into specially designed plastic blocks (20 mm x $20 \mathrm{~mm} \times 20 \mathrm{~mm}$ ) and waited until it became hard. Cubes that were taken out of blocks were kept in $2.3 \%$ formalin solution. They were then stored in distilled water for 48 hours. 
Prior to the actual experiments, in order to get used to the material, patients were asked to chew the testing material for many times until the testing material was ready to be swallowed. In the preliminary study, it was determined to use fixed numbers of chewing and decided 15 times was sufficient for the testing material get ready to be swallowed. After chewing process was complete, patients spitted the material in a container. After rinsing the material three times, they were collected in the same container. In order to calculate the masticatory efficiency, a pilot study was made to determine the required sieve diameters. Chewed material was washed in fine sieves having 3.15 and $0.5 \mathrm{~mm}$ hole diameters with water under pressure for 30 seconds. Gelatin particules collected from fine sieves were placed on filter papers. These filter papers were dried at $80^{\circ} \mathrm{C}$ for 24 hours. Dried filter papers were weighed in a scale and net weight of the gelatin particules were calculated by substracting the weight of the filter paper.

\section{Statistical analysis}

Data were analyzed using a statistical software package for Windows 16.01, (SPSS, SPSS Inc, Illinois, USA). One way analysis of variance (ANOVA) and Dunnett T3 analysis were used to compare the data from maximum mouth opening, protrusion, lateral excursions, masticatory efficiencies and chewing areas between pre-and post-treatment. In the case of significant differences between groups, Bonferroni posthoc test was used. Chi-square and McNemar Bowker tests were used for the comparison of results for chewing cycles. $P$ values less than 0.001 were considered statistically significant for all statistical tests.

\section{Results}

After splint therapy, significant decrease was observed in muscle pain, TMJ pain, headache, chewing difficulty in both MD and DDD patients $(p=0.000)$ (Table 1). Joint sounds were determined in 18 of the DDD patients before treatment but after splint use 2 patients still had joint sounds. 
While maximum mouth opening showed significant improvement after splint therapy in MD $(p=0.000)$ and DDD $(p=0.000)$ patients, lateral excursion, protrusion, laterotrusion of the affected and unaffected sides did not show significant changes compared to the baseline (Tables 2a-b). Maximum mouth opening was not significantly different from those of healthy subjects in both MD and DDD patients $(p>0.05)$.

Among healthy individuals and MD and DDD patients chewing cycle patterns of the affected and unaffected sides at the frontal plane were mainly F-I followed by F-II type. Healthy subjects did not present F-III (Tables 3a-b). Chewing cycle patterns at the frontal plane did not show significant difference between before and after treatment $(p>0.05)$. At the sagital plane, for MD and DDD patients, on the affected and unaffected sides, frequently S-I type was observed. No significant difference was found before and after treatment $(p>0.05)$ (Tables $4 a-b)$. At the horizontal plane, for MD and DDD patients, on the affected and unaffected sides, distribution of the incidence of $\mathrm{H}-\mathrm{I}$ and $\mathrm{H}-\mathrm{II}$ were not statistically significant before and after therapy $(p>0.05)$ (Tables 5a-b).

Masticatory efficiency for MD and DDD patients showed significant improvement after therapy according to both measurement methods (Table 6). But the MD and DDD did not show significant diffrences between each other. When the results from Method 1 ( $3.15 \mathrm{~mm}$ sieve) is considered, healthy patients did not show significant differences compared to MD and DDD after therapy $(p>0.05)$ but Method 2 showed that healthy patients could chew better $(p<0.0001)$.

Chewing cycle areas for MD and DDD patients showed significant improvement after therapy (Table 7). Chewing cycle areas for healthy individuals were significantly higher compared to baseline situations for MD and DDD patients but after therapy there were no significant differences between groups $(p>0.05)$. 


\section{Discussion}

Today, with the progress in equipments that record the jaw movements, skeleton-muscle system disorders could be easily diagnosed. Various jaw recording systems have developed over the years and used frequently in the clinics. ${ }^{9}$ In 1974 , Lewin et al. ${ }^{10}$ tried a magnet on mandibular central incisors to record jaw movements and subsequently in 1978, Lewin and Nickel ${ }^{11}$ developed the electrognathography (EEG). This device made it possible to record the whole mandibular movements. In 1985, Maruyama et al. ${ }^{12}$ introduced the gnathograph (GG) system where a magnet was placed onto mandibular central incisors and face-bow was assembled by placing it in the ears and centering the nose. SGG could record the chewing functions clinically based on the recorded cycles. In 1975, Jankelson ${ }^{13}$ introduced another magnetometric system. The magnet was placed at the centre of the sensor and the signals were recorded on the frontal, sagital and horizontal planes.

Chewing cycles have been classified according to gender, ${ }^{14,15}$ age,$^{16-19}$ food type ${ }^{20-24}$ malocclusion, ${ }^{25}$ occlusion, ${ }^{26}$ dentofacial anomalies,${ }^{27}$ craniomandibular disorders, ${ }^{28}$ xerostomia, ${ }^{29} \mathrm{TMD}^{30,31}$ and the effect of juvenile rheumatoid arthritis ${ }^{32}$ of the TMJ. In these studies, characteristic chewing cycles were recorded at frontal, sagital and horizontal planes and then classified. Ahlgren, ${ }^{33}$ was the first author who classified the chewing cycles on the frontal plane into seven classes. He stated that the first three chewing cycle group were seen in individuals with normal occlusion, the other four groups were seen in individuals with malocclusion. In another study, patients with TMD were shown to present more variations in chewing cycles than those of the healthy individuals. ${ }^{34}$ In other studies, chewing cycles were either classified into four ${ }^{30,31}$ or three ${ }^{35,36}$ groups at the frontal plane. In the classification of Kuwahara et al., ${ }^{34}$ the main concern was the point of the closed cycle in on the chewing or balance side, according to Sato et al., ${ }^{35}$ the jaw should be on the moving or unmoving side during the cycle and the lateral side width. On the other hand, at the sagital plane, some authors ${ }^{30,31,35-37}$ considered the chewing cycle into two groups according to anterior-posterior width. 
Only Sato et al. ${ }^{35,36}$ classified the chewing cycles on the horizontal plane in two groups. In the study of Ahlgren, ${ }^{25}$ the classification of Sato was used since it was more understandable and condyle movements could be observed easily. In order to evaluate the chewing cycles and condyle movement limitation without difficulty, lateral cycle width on the frontal plane is important. Maruyama et al., ${ }^{12}$ stated that the classification should be done with similar chewing cycles that happens consecutively instead of one chewing cycle. By choosing individuals who had one side muscular disorder and one side internal derangement, the evaluation of differences between chewing cycles of the affected and the unaffected sides could be observed.

In this study, with healthy individuals, drop-shaped chewing pattern $(\mathrm{F}-\mathrm{I})$ at the frontal plane was seen more often but narrow and long chewing cycle (F-III) was never observed. In patients having MD, after treatment, F-III chewing cycle decreased but F-I chewing cycle at the affected and unaffected sides increased. Also in these patients, lateral cycle width decreased especially in those who had narrow, long (F-III) chewing cycle having severe muscle spasm. Because the pain occurred during chewing, the patients moved their jaws only vertically and avoided lateral movements.

At the sagital plane, healthy individuals presented often S-II chewing cycles. Similar observations were made in the study of Jemt and Olsson. ${ }^{38} \mathrm{~S}-\mathrm{I}$ chewing cycle that was narrower in the patients who had $M D$, was observed very often before treatment at both affected and unaffected side. Interestingly, there was no significant change after treatment. At the horizontal plane, healthy individuals showed more $\mathrm{H}-\mathrm{I}$ chewing cycle but MD patients showed $\mathrm{H}-\mathrm{I}$ chewing cycle only at the affected side. The unaffected side at this patient group, showed mainly $\mathrm{H}-\mathrm{Il}$ chewing cycle. Again after treatment, no significant change was observed.

With the DDD patients, at the frontal plane initially F-I chewing cycle was more common but after treatment, the unaffected side shifted significantly to F-II and F-III chewing cycles. In similar studies, it was stated that the chewing cycles of individuals who had DDD were different from chewing cycles of 
individuals with healthy joint anatomy. ${ }^{30,31}$ While lateral chewing movements were postulated to be reduced in children who had chronic arthritis in one study, ${ }^{32}$ in another study, ${ }^{35}$ no difference was seen in the chewing cycles at the affected side after treatment. On the contrary, significant improvements were seen in the chewing cycles of individuals who had F-III at the unaffected side. In a study, where different conservative treatment methods were used, patients having disc displacement with reduction showed similar chewing cycles to healthy individuals after 12 months. ${ }^{39}$ Kuwahara et al. ${ }^{40}$ injected sodium hyaluronic acid to cavum articulare of patients who had TMD and had chewing movements different from those of the healthy patients. With this route, chewing cycles of the patients became similar to those of the healthy individuals after 19 months. They added that when the patients with disc displacement without reduction did not receive medical treatment, their chewing cycles could not get better. In this study, where no medication was provided to the patients, at the unaffected side of the DDD patients, the dislocated joint disc on the affected side restricted the sliding movement of the condyle and hindered the lateral movement of the mandibula. For this reason, F-II and F-III chewing cycles occured more frequently. In contrast, chewing cycles were of the affected side were similar to those of the healthy individuals. During chewing with the affected side, the condyle on the affected side changed its place to the lateral side with the Bennett movement. Hence, mandible movements were not affected. On the other hand, during chewing with the unaffected side, there was a restriction of condyle changing its place since it did not have a normal anatomic relation with the joint disc. For DDD patients, after achieving the healthy condyle-disc relation on the affected side, chewing cycles became better since joint condyle could make its normal movements. For DDD patients, if reducing the pain and increasing the mouth opening had been the only purpose, only perpendicular improvement would have been seen in the chewing cycles. Since there was no remarkable improvement on the lateral side, chewing cycle and masticatory efficiency did not change.

At the sagittal plane, DDD patients presented S-I chewing cycle both at the affected and unaffected sides at baseline. Splint therapy did not make any significant change. For the same group of patients, at 
the horizontal plane, $\mathrm{H}-\mathrm{Il}$ chewing cycle was seen at the affected side and $\mathrm{H}-\mathrm{I}$ at the unaffected side at baseline. Again, splint therapy did not make significant change. Based on these findings, it can be said that computerized mandible scanner can help to make proper diagnostics before treatment and especially to determine the intra- or extra-articuler disorders. They can be considered useful for observing joint movements but information on the physiopathology of intra-articular tissues and disc position cannot be obtained. Thus, the sum of all information should be considered from all perspectives. Yet, splint therapy for both MD and DDD patients for the duration of 6 months may not change the situation at all planes according to the kinesiography method. In that respect, kinesiography methods could provide some tendencies but caution should be exercised on the definitive diagnostics, progress or improvement in the disorder.

Masticatory efficiency is one of the most important parameters in evaluating the chewing function of TMD patients. ${ }^{41}$ Usually these patients have reduced masticatory efficiency compared to healthy individuals. ${ }^{42}$ After treatment, generally masticatory efficiency of MD and DDD patients increase ${ }^{43,44}$ but remains less than healthy individuals. ${ }^{35,36,45}$ Likewise in this study, masticatory efficiency of MD and DDD patients improved but did not reach the values of healthy individuals. Maximum masticatory efficiency is related to the width and number of contacts occur when the teeth are about to occlude. ${ }^{46,47}$ In this study, most probably masticatory efficiency was reduced since the lateral width of chewing cycles of the patients was reduced and therefore the gliding contact and gliding periods were reduced. If we intended to increase the masticatory efficiency, the chewing cycle should have made more lateral movements. But with the increase in lateral width in chewing cycles after treatment, a significant improvement was seen in masticatory efficiency, as there was an increase of chewing cycles and gliding contacts.

Chewing performances of DDD patients were lower than healthy individuals. Patients having severe pain showed similar performance with the healthy individuals because the former tried hard to cut the food into pieces. ${ }^{44}$ The choice of treatment method and the continuity of the treatment is a very 
important factor on masticatory efficiency. Especially for individuals who had internal derangement, without relocation of joint disc, which was dislocated, long term and permanent treatment could not be managed and the comfort of the patient could not be increased. No study was found to make comparisons of the calculated chewing areas of the TMD patients.

Evans and Lewin ${ }^{48}$ analysed the chewing cycle areas in two African ethnic groups and the approximate chewing cycle was $206.72 \mathrm{~mm}^{2}$. Barciela et al. ${ }^{49}$ made graphic records on the frontal plane from 30 patients aged between 21 and 32 . They found that chewing cycle was $167.96 \mathrm{~mm}^{2}$ during chewing with the right side and $173.64 \mathrm{~mm}^{2}$ with the left side. While Chew et al. ${ }^{21}$ calculated the chewing area on the horizontal plane, Nishigawa et al. ${ }^{51}$ evaluated the chewing area in percentage. In this study, the chewing cycle area was $142.9 \mathrm{~mm}^{2}$ in healthy individuals. While the chewing cycle area increased from $109.65 \mathrm{~mm}^{2}$ to $136.75 \mathrm{~mm}^{2}$ in MD patients, it increased from $98.32 \mathrm{~mm}^{2}$ to $123.8 \mathrm{~mm}^{2}$ in DDD patients after treatment. The increase of chewing areas after treatment was evidently related to the improvement of chewing cycles and the increase of intraborder movements.

\section{Conclusions}

1. For patients with unilateral muscular disorders (MD) or unilateral disc derangement disorders (DDD), splint therapy may be beneficial to eliminate the muscle pain, TMJ pain, headache, chewing difficulty and reduce joint sounds and improve maximum mouth opening.

2. Splint treatment for lateral excursion, protrusion, laterotrusion of the affected and unaffected sides could be beneficial for MD patients.

3. Chewing cycle patterns of the affected and unaffected sides in MD and DDD patients were similar to healthy individuals before and after splint therapy. Changes seen at the frontal plane after treatment were not observed at the sagittal and horizontal planes. 
4. Masticatory efficiency of MD and DDD patients showed significant improvement after therapy but depending on the measurement method healthy patients seemed to chew better.

5. After splint therapy, chewing cycle areas for both MD and DDD patients showed significant improvement indicating increased intraborder movements. 


\section{References}

1. Okeson JP: Management of Temporomandibuler Disorders and Occlusion $7^{\text {rd }}$ edition., Mosby Inc. 2012. p. 129-136.

2. Zarb GA, Thompson GW: Assesment of clinical treatment of patients with temporomandilar dysfunction J Prosthet Dent 1970; 24: 542-554.

3. Cohen SR: Follow-up evaluation of 105 patients with myofacial pain- dysfunction syndrome. J Am Dent Assoc 1978; 97: 825- 828.

4. Mao J, Stein RB, Osborn JW: Fatigue in human jaw muscles. Review. J Orofac Pain 1993; 7: 135142.

5. Ash M, Ramfjord S: Occlusion, 4th edn, Nueva Editorial Interamericana, Espana: 1994. p.195.

6. Williamson EH, Sheffield JW: The treatment of internal derangements of the TMJ. A survey of 300 cases. J Craniomand Pract 1987; 5: 119-124.

7. Agerberg G: Maksimum mandibular movement in young men and women. Swed Dent J 1974; 76: 81102.

8. Miller VJ, Karic VV, Myers SL, Exner HV: Myogenous temporomandibular disorder patients and the temporomandibular opening index. J Oral Rehabil 2000; 27: 720-722.

9. Hannam AG: The measurement of jaw motions. Current controversies in temporomandibular disorders. Chicago: Quintessence, 1992, p. 130-137.

10. Lewin A, van Rensburg LB, Lemmer J: A method of recording the movement of a point on the jaw. $J$ Dent Assoc S Afr 1974; 29: 395-397.

11. Lewin A, Nickel B: The full description of jaw movement. J Dent Soc S Afr 1978; 33: 261-267. 
12. Maruyama T, Higashi K, Mizumori T, Miyauchi S, Kuroda T: Clinical studies on consistency of chewing movements. Chewing path for the same food: J Osaka Univ Dent Sch 1985; 25: 49-61.

13. Jankelson B, Swain CW, Crane PF, Radke JC: Kinesiometric instrumentation: A new technology. J Am Dent Assoc 1975; 90: 834.

14. Neill DJ, Howell PGT: Computerized kinesiography in the study of mastication in dentate subjects. $J$ Prosthet Dent 1986; 55: 629-638.

15. Gerstner GE, Parekh VV: Evidence of sex-specific differences in masticatory jaw movement patterns. J Dent Res 1997; 76: 796-806.

16. Gibbs $\mathrm{CH}$, Wickwire NA, Jacobson AP, Lundeen HC, Mahan PE, Lupkiewicz SM: Comparison of typical chewing patterns in normal children and adults. J Am Dent Assoc 1982; 105: 33-42.

17. Karlsson S, Carlsson GE: Characteristics of mandibular masticatory movement in young and elderly dentate subjects. J Dent Res 1990; 69: 473-476.

18. Huang X, Zhang G, Herring SW: Age changes in mastication in the pig. Comp Biochem Physiol 1994; 107A: 647-654.

19. Snipes WB, Throckmorton GS, Buschang PH: Normal masticatory function of girls and young women: Mandibular masticatory movements. Am J Human Biol 1998; 10: 53-62.

20. Lucas PW, Ow RK, Ritchie GM, Chew CL, Keng SB: Relationship between jaw movement and food breakdown in human mastication. J Dent Res 1986; 65: 400-404.

21. Chew CL, Lucas PW, Tay DKL, Keng SB, Ow RKK: The effect of food texture on the replication of jaw movements in mastication. J Dent 1988; 16: 210-214.

22. Huang X, Zhang G, Herring SW: Effects of oral sensory afferents on mastication in the miniature pig. J Dent Res 1993; 72: 980-986.

23. Deat DG, Watanabe M, Sasaki K: Association between the interarch distance and food bolus size in the early phase of mastication. J Prosthet Dent 1995; 74: 367-372. 
24. Peyron MA, Maskawi K, Woda A, Tanguay R, Lund JP: Effects of food texture and sample thickness on mandibular movement and hardness assessment during biting in man. J Dent Res 1997; 76: 789795.

25. Ahlgren J: Pattern of chewing and malocclusion of the teeth: A clinical study. Acta Odontol Scand 1967; 25: 3-13.

26. Pröschel $Y$, Hoffman PM: Front chewing patterns of the incisor point and their dependence on the resistance of food and type of occlusion. J Prosthet Dent 1988; 59: 617.

27. Youssef RE, Throckmorton GS, Ellis EI, Sinn DP: Comparison of habitual masticatory activity before and after orthognathic surgery. J Oral Maxillofac Surg 1997; 55: 699-707.

28. Kuwabara T, Miyauchi S, Maruyama T: Clinical study on chewing movement in anterior disk displacement with reduction. J Japan Prosthodont Soc 1988; 32, 10.

29. Hamlet S, Faull J, Klein B, Aref A, Fontanesi J, Stachler R, Shamsa F, Jones L, Simpson M: Mastication and swallowing in patients with postirradiation xerostomia. Int J Radiat Oncol Biol Phys 1997; 37: 789-796.

30. Kuwahara T, Bessette RW, Maruyama T: Chewing pattern analysis in TMD patients with and without internal derangement. Part I. J Craniomand Pract 1995a; 13: 8-14.

31. Kuwahara T, Bessette RW, Maruyama T: Chewing pattern analysis in TMD patients with and without internal derangement. Part II. J Craniomand Pract 1995b; 13: 93-98.

32. Kjellberg H, Kliaridis S, Karlsson S: Characteristics of masticatory movements and velocity in children with juvenile chronic arthritis. J Orofacial Pain 1995; 9: 64-72.

33. Ahlgren J: Mechanism of mastication. A quantitative cinematographic and electromyographic study of masticatory movements in children, with special reference to occlusion of the teeth. Acta Odont Scand 1966; 24: Supp. 44.

34. Kuwahara T, Miyauchi S, Maruyama T: Clinical classification of the patterns of mandibular movements during mastication in subjects with TMJ disorders. Int J Prosthodont 1992; 5: 122-129. 
35. Sato S, Goto S, Takanezawa H: EMG and kinesiographic study in patients with nonreduction disk displacement of the temporomandibular joint. Oral Surg Oral Med Oral Pathol Oral Radiol Endod 1996; 81: 516 .

36. Sato S, Nasu F, Motegi K: Natural course of nonreducing disc displacement of the temporomandibular joint: Changes in chewing movement and masticatory efficiency. J Oral Maxillofac Surg 2002; 60: 867-872.

37. De Loat A, Van Steenberghe D: Occlusal relationships and temporomandibular joint dysfunction, Part I. Epidemiological Findings. J Prosthet Dent 1985; 54: 835-842.

38. Jemt $\mathrm{T}$, Olsson $\mathrm{K}$ : Computer based analysis of the single chewing cycle during mastication in repeated registrations. J Prosthet Dent 1981; 52: 437-444.

39. Shimomura T: Study on mandibular movements before and after treatment in the patients with anterior displacement of the TMJ disk without reduction. Shikwa Gakuho 1991; 91, 999.

40. Kuwahara T, Bessett RW, Maruyama T: The influence of postoperative treatment on the results of TMJ meniscectomy. Part II: Comparison of chewing movement. J Craniomand Pract 1996; 14: 121.

41. Henrikson T, Ekberg E, Nilner M: Masticatory efficiency and ability in relation to occlusion and mandibular dysfunction in girls. Int J Prosthodont 1998; 11: 125.

42. Ekberg EC, Vallon D, Nilner M: The efficacy of appliance therapy in patients with temporomandibular disorders of mainly myogenous origin. A randomized, controlled, short-term study. $J$ Orofac Pain 2003; 17: 133-139.

43. Rammelsberg $\mathrm{P}$, Jager L, Bohm A, Lentner E, Pospiech P, Gernet W: Subjektive und objektivierbare Befunde bei anterioren Diskusverlagerungen ohne Reposition im Kiefergelenk. Dtsch Zahnarztl Z 1997; 52: 338-341.

44. Peroz I, Tai S: Masticatory performance in patients with anterior disk displacement without reduction in comparison with symptom-free volunteers. Eur J Oral Sci 2002; 110: 341-344. 
45. Sato S, Ohta M, Sawatari M, Kawamura H, Motegi K: Occlusal contact area, occlusal pressure, bite force and masticatory efficiency in patients with ADD of the TMJ. J Oral Rehabil 1999; 26: 906-911.

46. Woda A, Vigneron P, Kay D: Nonfunctional and functional occlusal contacts: A review of literature. J Prosthetic Dent 1979; 42: 335.

47. Yamashita JP, Rugh JD: Does chewing performance depend upon a specific masticatory pattern? J Oral Rehabil 1999; 26: 547-53

48. Evans WG, Lewin A: Some characteristics of mandibular movement in a group of San. J Dent Assoc S Afr 1986; 41: 543.

49. Barciela CN, Fernandez JM, Martin B, Rilo B, Suarez J, Gonzales J, Varela P: Analysis of the area and length of masticatory cycles in male and female subjects. J Oral Rehabil 2002: 29: 1160-1164.

50. Nishigawa K, Nakano M, Bando E, Clark GT: The relationship between lateral border movements of the mandible and the determinants of the occlusion. J Prosthet Dent 1991; 66: 486. 


\section{Captions to the legends and tables}

\section{Tables}

Table 1 Symptoms before and after splint therapy of patients with muscle disorder and disc derangement disorder.

Tables 2a-b Intraborder movement measurements $(\mathrm{mm})$ of $\mathbf{a})$ muscular disorder patients and b) disc derangement disorder patients before and after treatment compared to healthy individuals. $P$ values represent significant differences between baseline and post-treatment situations.

Tables 3a-b Chewing cycle patterns of a) affected side b) unaffected side on the frontal plane for muscular disorder and disc derangement disorder patients before and after treatment compared to healthy individuals. F-I: drop; F-II: semi-oval; F-III: narrow-long.

Tables 4a-b Chewing cycle patterns of a) affected side b) unaffected side on the sagittal plane for muscular disorder and disc derangement disorder patients before and after treatment compared to healthy individuals. S-I: $<2 \mathrm{~mm}$; S-II: $>2 \mathrm{~mm}$.

Tables 5a-b Chewing cycle patterns of a) affected side b) unaffected side on the horizontal plane for muscular disorder and disc derangement disorder patients before and after treatment compared to healthy individuals. $\mathrm{H}-\mathrm{I}:<2 \mathrm{~mm}$; $\mathrm{H}-\mathrm{II}:>2 \mathrm{~mm}$.

Table 6 Masticatory efficiency of patients with muscular disorder and disc derangement disorder before and after treatment compared to healthy individuals. Measurements are based on te weight of gelatin particules collected on the two diffremt types of sieves $(g)$. P values represent significant differences between baseline and post-treatment situations. 
Table 7 Chewing cycle area $\left(\mathrm{mm}^{2}\right)$ of patients with muscular disorder and disc derangement disorder before and after treatment compared to healthy individuals. $\mathrm{P}$ values represent significant differences between baseline and post-treatment situations.

\section{Figures}

Figure 1 Photo of the patient during neuromuscular instrumentation with the mandible tracker magnet making the trace.

Figure 2 The part of computerized mandible scanner that registers the jaw movements to the computer applied to the patient by the support of nose and head. 
Tables:

\begin{tabular}{|l|l|l|l|l|l|l|}
\hline & \multicolumn{2}{|l}{ Muscular Disorder (MD) (n=20) } & \multicolumn{2}{|c|}{$\begin{array}{l}\text { Disc Derangement Disorder } \\
\text { (DDD) (n=20) }\end{array}$} \\
\cline { 2 - 7 } & $\begin{array}{l}\text { Before } \\
\text { Treatment }\end{array}$ & $\begin{array}{l}\text { After } \\
\text { Treatment }\end{array}$ & \multicolumn{1}{|c|}{$p$} & $\begin{array}{l}\text { Before } \\
\text { Treatment }\end{array}$ & $\begin{array}{l}\text { After } \\
\text { Treatment }\end{array}$ & $p$ \\
\hline Muscle Pain (0-10) & $7.3 \pm 1.1$ & $2 \pm 0.9$ & 0.000 & $5 \pm 2$ & $1.2 \pm 1.1$ & 0.000 \\
\hline TMJ Pain (0-10) & $2.3 \pm 1.1$ & $1.0 \pm 0.9$ & 0.001 & $7.5 \pm 1.7$ & $3.0 \pm 0.9$ & 0.000 \\
\hline Headache (0-10) & $7 \pm 1.3$ & $2.3 \pm 1.2$ & 0.000 & $6 \pm 1.6$ & $2.5 \pm 1.3$ & 0.000 \\
\hline Chewing difficulty (0-10) & $7 \pm 0.8$ & $2 \pm 0.7$ & 0.000 & $8 \pm 1.2$ & $3.0 \pm 1.1$ & 0.000 \\
\hline Joint Sounds & 0 & 0 & - & 18 & 2 & - \\
\hline
\end{tabular}

Table 1 Symptoms before and after splint therapy of patients with muscle disorder and disc derangement disorder. 


\begin{tabular}{|l|l|l|l|l|}
\hline Muscular Disorder (MD) & Before Treatment & After Treatment & $\begin{array}{l}\text { Healthy } \\
\text { Individuals }\end{array}$ & $\mathrm{p}$ \\
\hline Maximum mouth opening & $44.14 \pm 5.84$ & $49.49 \pm 5.19$ & $48.56 \pm 6.09$ & 0.000 \\
\hline Protrusion & $8 \pm 2.71$ & $9.48 \pm 2.51$ & $9.61 \pm 3.46$ & 0.073 \\
\hline Laterotrusion of affected side & $6.44 \pm 2.03$ & $6.60 \pm 1.56$ & $6.72 \pm 1.02$ & 0.730 \\
\hline $\begin{array}{l}\text { Laterotrusion of unaffected } \\
\text { side }\end{array}$ & $6.16 \pm 1.53$ & $6.69 \pm 1.5$ & $6.72 \pm 1.02$ & 0.186 \\
\hline
\end{tabular}

Table 2a Intraborder movement measurements $(\mathrm{mm})$ of muscular disorder patients before and after treatment compared to healthy individuals. $\mathrm{P}$ values represent significant differences between baseline and post-treatment situations.

\begin{tabular}{|l|l|l|l|l|}
\hline $\begin{array}{l}\text { Disc Derangement Disorder } \\
\text { (DDD) }\end{array}$ & Before Treatment & After Treatment & $\begin{array}{l}\text { Healthy } \\
\text { Individuals }\end{array}$ & $p$ \\
\hline Maximum mouth opening & $32.94 \pm 6.83$ & $40.59 \pm 7.49$ & $48.56 \pm 6.09$ & 0.000 \\
\hline Protrusion & $6.59 \pm 1.82$ & $6.99 \pm 1.76$ & $9.61 \pm 3.46$ & 0.483 \\
\hline Laterotrusion of affected side & $4.87 \pm 1.54$ & $5.43 \pm 2.12$ & $6.72 \pm 1.02$ & 0.360 \\
\hline Laterotrusion of unaffected side & $5.43 \pm 1.47$ & $6.21 \pm 2.51$ & $6.72 \pm 1.02$ & 0.221 \\
\hline
\end{tabular}

Table 2b Intraborder movement measurements $(\mathrm{mm})$ of disc derangement disorder patients before and after treatment compared to healthy individuals. $P$ values represent significant differences between baseline and posttreatment situations. 


\begin{tabular}{|c|c|c|c|c|c|}
\hline$\pi$ & $\begin{array}{l}\text { Healthy } \\
\text { Individuals }\end{array}$ & Muscular & rder (MD) & $\begin{array}{l}\text { Disc } \\
\text { Disorder ( }\end{array}$ & $\begin{array}{l}\text { Derangement } \\
\text { D) }\end{array}$ \\
\hline & & $\begin{array}{l}\text { Before } \\
\text { Treatment }\end{array}$ & $\begin{array}{l}\text { After } \\
\text { Treatment }\end{array}$ & $\begin{array}{l}\text { Before } \\
\text { Treatment }\end{array}$ & $\begin{array}{l}\text { After } \\
\text { Treatment }\end{array}$ \\
\hline F-I & 14 & 10 & 13 & 13 & 15 \\
\hline F-II & 6 & 8 & 6 & 5 & 5 \\
\hline F-III & - & 2 & 1 & 2 & - \\
\hline Tota & 20 & 20 & 20 & 20 & 20 \\
\hline
\end{tabular}

Table 3a Chewing cycle patterns of affected side on the frontal plane for muscular disorder and disc derangement disorder patients before and after treatment compared to healthy individuals. F-I: drop; F-II: semi-oval; F-III: narrow-long.

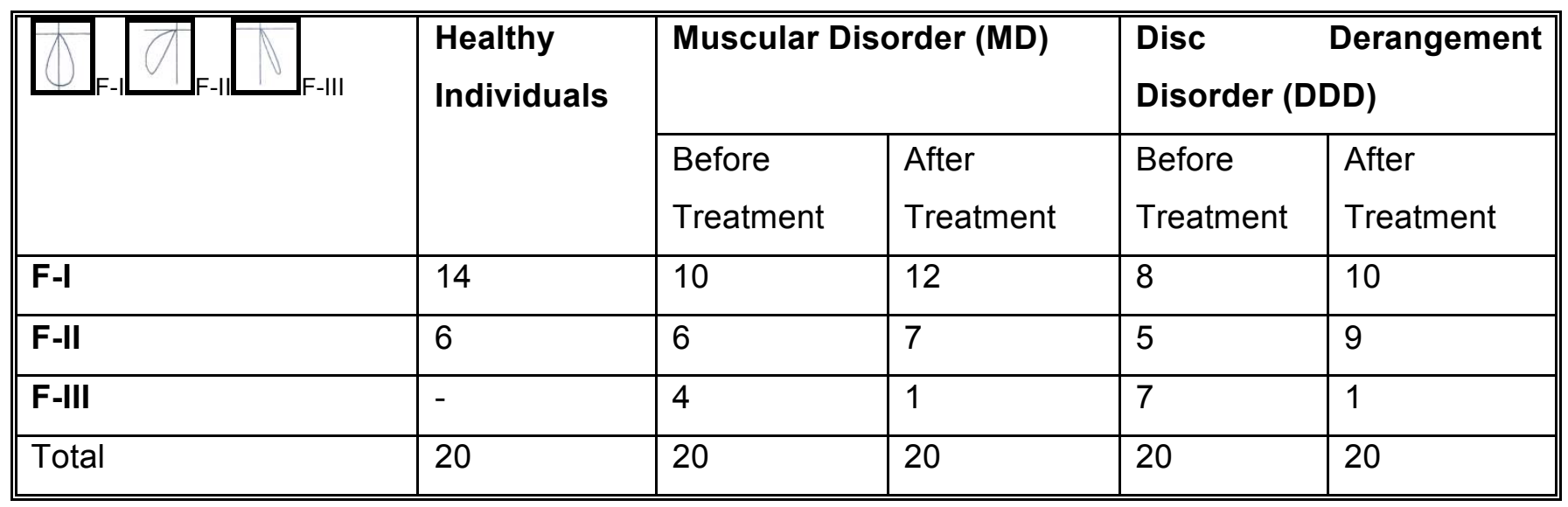

Table 3b Chewing cycle patterns of unaffected side on the frontal plane for muscular disorder and disc derangement disorder patients before and after treatment compared to healthy individuals. F-I: drop; F-II: semioval; F-III: narrow-long. 


\begin{tabular}{|c|c|c|c|c|c|}
\hline 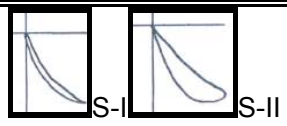 & $\begin{array}{l}\text { Healthy } \\
\text { Individuals }\end{array}$ & Muscular & order (MD) & $\begin{array}{l}\text { Disc } \\
\text { Disorder (I }\end{array}$ & $\begin{array}{l}\text { Derangement } \\
\text { DD) }\end{array}$ \\
\hline & & $\begin{array}{l}\text { Before } \\
\text { Treatment }\end{array}$ & $\begin{array}{l}\text { After } \\
\text { Treatment }\end{array}$ & $\begin{array}{l}\text { Before } \\
\text { Treatment }\end{array}$ & $\begin{array}{l}\text { After } \\
\text { Treatment }\end{array}$ \\
\hline S-I & 8 & 12 & 13 & 13 & 14 \\
\hline S-II & 12 & 8 & 7 & 7 & 6 \\
\hline Total & 20 & 20 & 20 & 20 & 20 \\
\hline
\end{tabular}

Table 4a Chewing cycle patterns of affected side on the sagittal plane for muscular disorder and disc derangement disorder patients before and after treatment compared to healthy individuals. S-I: $<2 \mathrm{~mm}$; S-II: $>2 \mathrm{~mm}$.

\begin{tabular}{||l|l|l|l|l|l||}
\hline \multirow{2}{*}{\begin{tabular}{l} 
Individuals \\
\cline { 3 - 6 }
\end{tabular}} & \multirow{2}{*}{$\begin{array}{l}\text { Healthy } \\
\text { IS-II }\end{array}$} & \multicolumn{2}{|l||}{ Muscular Disorder (MD) } & \multicolumn{2}{|l|}{$\begin{array}{l}\text { Disc Derangement } \\
\text { Disorder (DDD) }\end{array}$} \\
\cline { 3 - 7 } & & $\begin{array}{l}\text { Before } \\
\text { Treatment }\end{array}$ & $\begin{array}{l}\text { After } \\
\text { Treatment }\end{array}$ & $\begin{array}{l}\text { Before } \\
\text { Treatment }\end{array}$ & $\begin{array}{l}\text { After } \\
\text { Treatment }\end{array}$ \\
\hline S-I & 8 & 16 & 14 & 11 & 13 \\
\hline S-II & 12 & 4 & 6 & 9 & 7 \\
\hline Total & 20 & 20 & 20 & 20 & 20 \\
\hline \hline
\end{tabular}

Table 4b Chewing cycle patterns of unaffected side on the sagittal plane for muscular disorder and disc derangement disorder patients before and after treatment compared to healthy individuals. S-I: $<2 \mathrm{~mm}$; S-II: $>2$ $\mathrm{mm}$. 


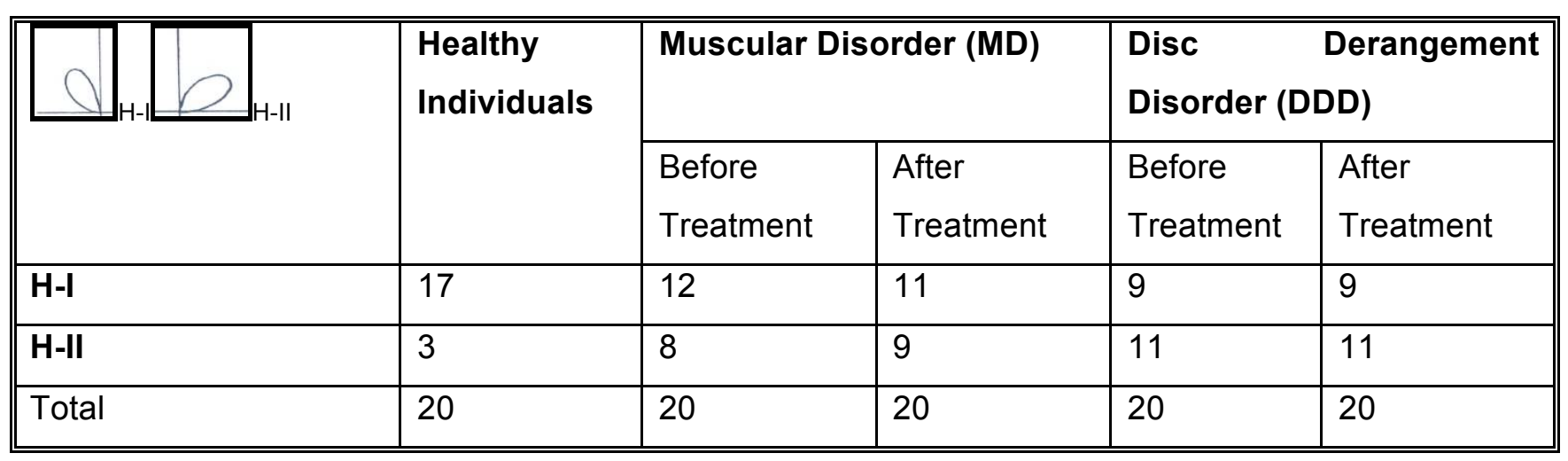

Table 5a Chewing cycle patterns of affected side on the horizontal plane for muscular disorder and disc derangement disorder patients before and after treatment compared to healthy individuals. $\mathrm{H}-\mathrm{I}$ : $<2 \mathrm{~mm}$; $\mathrm{H}-\mathrm{II}:>2$ $\mathrm{mm}$.

\begin{tabular}{|c|c|c|c|c|c|}
\hline$\Delta_{H-I} \bigcirc{ }_{H-I}$ & $\begin{array}{l}\text { Healthy } \\
\text { Individuals }\end{array}$ & Muscular & order (MD) & $\begin{array}{l}\text { Disc } \\
\text { Disorder ( }\end{array}$ & $\begin{array}{l}\text { Derangement } \\
\text { DD) }\end{array}$ \\
\hline & & $\begin{array}{l}\text { Before } \\
\text { Treatment }\end{array}$ & $\begin{array}{l}\text { After } \\
\text { Treatment }\end{array}$ & $\begin{array}{l}\text { Before } \\
\text { Treatment }\end{array}$ & $\begin{array}{l}\text { After } \\
\text { Treatment }\end{array}$ \\
\hline $\mathrm{H}-\mathrm{I}$ & 17 & 7 & 9 & 11 & 9 \\
\hline $\mathrm{H}-\mathrm{II}$ & 3 & 13 & 11 & 9 & 11 \\
\hline Toplam & 20 & 20 & 20 & 20 & 20 \\
\hline
\end{tabular}

Table 5b Chewing cycle patterns of unaffected side on the horizontal plane for muscular disorder and disc derangement disorder patients before and after treatment compared to healthy individuals. $\mathrm{H}-\mathrm{I}:<2 \mathrm{~mm}$; $\mathrm{H}-\mathrm{II}:>2$ $\mathrm{mm}$. 


\begin{tabular}{|c|c|c|c|c|c|c|c|}
\hline \multirow{3}{*}{$\begin{array}{l}3.15 \mathrm{~mm} \\
\text { sieve }(\mathrm{g})\end{array}$} & \multicolumn{3}{|c|}{ Muscular Disorder (MD) } & \multicolumn{3}{|c|}{ Disc Derangement Disorder (DDD) } & \multirow{3}{*}{$\begin{array}{l}\text { Healthy } \\
\text { Individuals }\end{array}$} \\
\hline & $\begin{array}{l}\text { Before } \\
\text { Treatment }\end{array}$ & $\begin{array}{l}\text { After } \\
\text { Treatment }\end{array}$ & $p$ & $\begin{array}{l}\text { Before } \\
\text { Treatment }\end{array}$ & $\begin{array}{l}\text { After } \\
\text { Treatment }\end{array}$ & $\mathrm{p}$ & \\
\hline & $0.665 \pm 0.076$ & $0.634 \pm 0.046$ & 0.033 & $0.695 \pm 0.027$ & $0.655 \pm 0.039$ & 0.000 & \\
\hline \multirow{2}{*}{$\begin{array}{l}0.5 \mathrm{~mm} \\
\text { sieve }(\mathrm{g})\end{array}$} & $\begin{array}{l}\text { Before } \\
\text { Treatment }\end{array}$ & $\begin{array}{l}\text { After } \\
\text { Treatment }\end{array}$ & $\mathrm{p}$ & $\begin{array}{l}\text { Before } \\
\text { Treatment }\end{array}$ & $\begin{array}{l}\text { After } \\
\text { Treatment }\end{array}$ & $\mathrm{p}$ & \multirow[t]{2}{*}{$0.187 \pm 0.040$} \\
\hline & $0.145 \pm 0.014$ & $0.155 \pm 0.015$ & 0.005 & $0.118 \pm 0.013$ & $0.138 \pm 0.016$ & 0.000 & \\
\hline
\end{tabular}

Table 6 Masticatory efficiency of patients with muscular disorder and disc derangement disorder before and after treatment compared to healthy individuals. Measurements are based on te weight of gelatin particules collected on the two diffremt types of sieves $(\mathrm{g})$. P values represent significant differences between baseline and post-treatment situations.

\begin{tabular}{|c|c|c|c|c|c|c|c|}
\hline \multirow{3}{*}{$\begin{array}{l}\text { Chewing cycle } \\
\text { area }\left(\mathrm{mm}^{2}\right)\end{array}$} & \multicolumn{3}{|c|}{ Muscular Disorder (MD) } & \multicolumn{3}{|c|}{$\begin{array}{lll}\text { Disc } & \text { Derangement } & \text { Disorder } \\
\text { (DDD) } & & \end{array}$} & $\begin{array}{l}\text { Healthy } \\
\text { Individuals }\end{array}$ \\
\hline & $\begin{array}{l}\text { Before } \\
\text { Treatment }\end{array}$ & $\begin{array}{l}\text { After } \\
\text { Treatment }\end{array}$ & $p$ & $\begin{array}{l}\text { Before } \\
\text { Treatment }\end{array}$ & $\begin{array}{l}\text { After } \\
\text { Treatment }\end{array}$ & $\mathrm{p}$ & \multirow[t]{2}{*}{$142.9 \pm 49.24$} \\
\hline & $109.65 \pm 42.87$ & $136.75 \pm 74.44$ & 0.033 & $98 \pm 32.28$ & $123.8 \pm 38.61$ & 0.000 & \\
\hline
\end{tabular}

Table 7 Chewing cycle area $\left(\mathrm{mm}^{2}\right)$ of patients with muscular disorder and disc derangement disorder before and after treatment compared to healthy individuals. $P$ values represent significant differences between baseline and post-treatment situations. 


\section{Figures:}

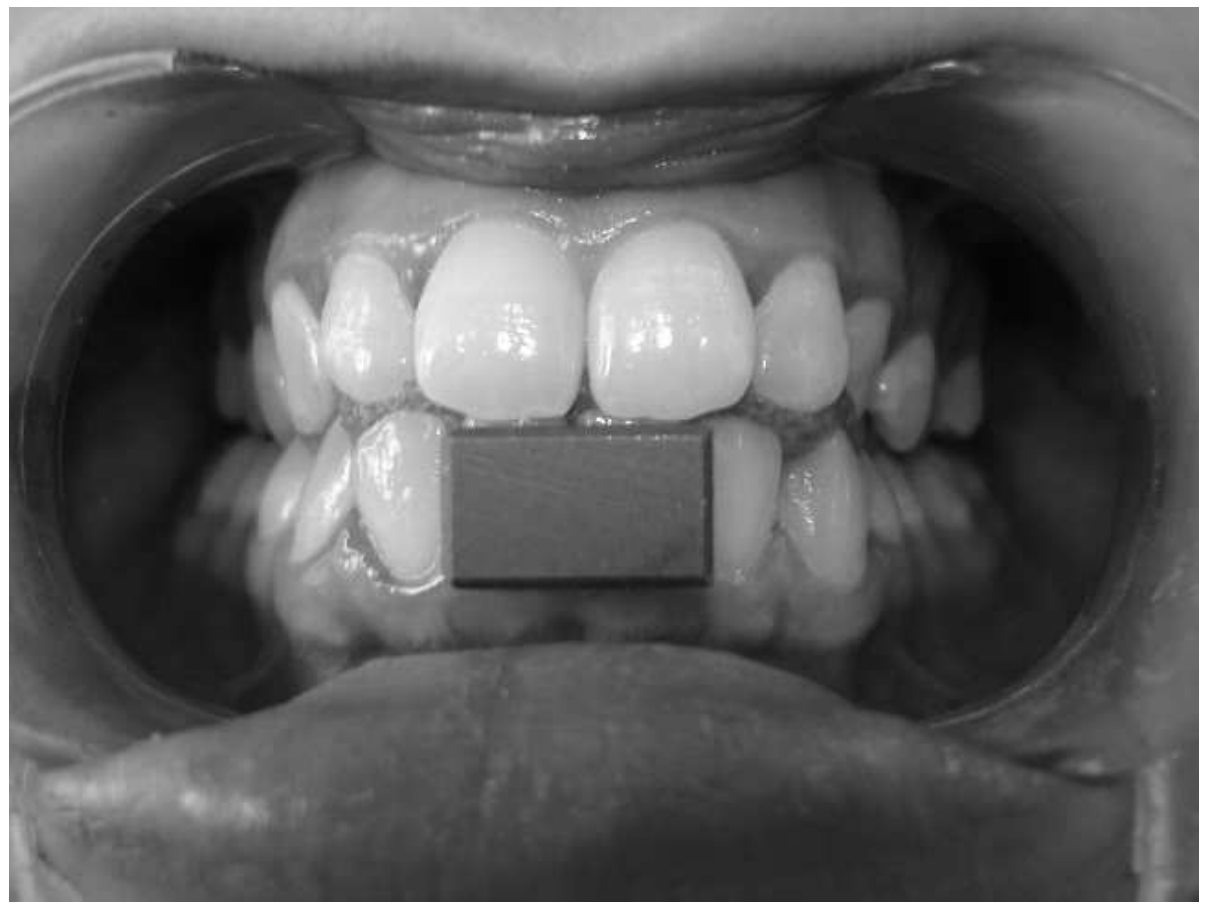

Figure 1 Photo of the patient during neuromuscular instrumentation with the mandible tracker magnet making the trace.

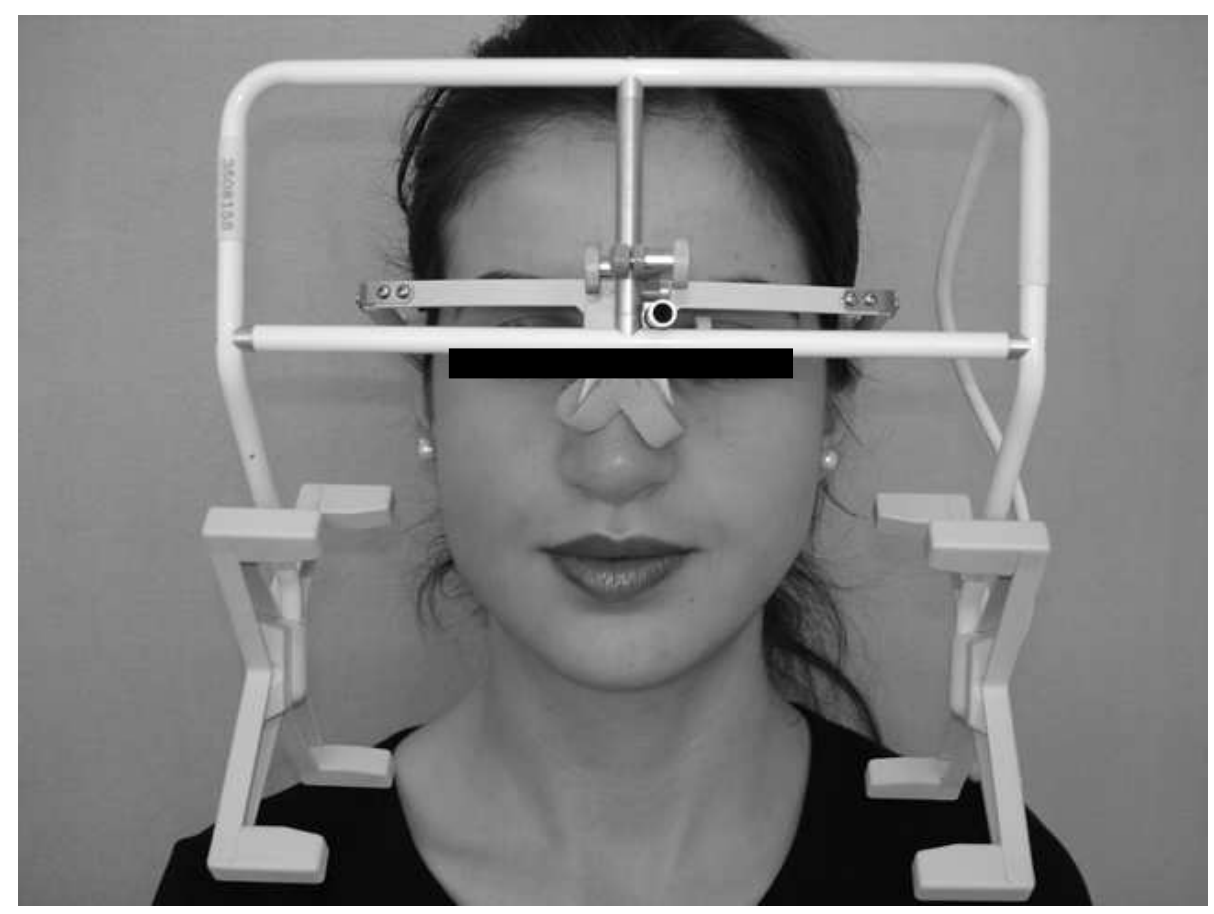

Figure 2 The part of computerized mandible scanner that registers the jaw movements to the computer applied to the patient by the support of nose and head. 